\title{
Analisis Pengaruh Faktor Modifikasi Respon SRPMK Struktur Gedung Beton Bertulang Pada Balok Kategori Desain Seismik D
}

\author{
Budi Rahmad Tangahu 1), Kasmat Saleh Nur 2), Mirzan Gani ${ }^{3)}$ \\ 1),2),3) Jurusan Teknik Sipil, Fakultas Teknik, Universitas Negeri Gorontalo \\ email: budirahmadtangahu@gmail.com
}

\begin{abstract}
Abstrak
Berdasarkan parameter kecepatan gelombang Kota Gorontalo masuk dalam kelas situs SD. Hal ini mengaruskan perencanaan bangunan bertingkat didesain sebagai Sistem Rangka Pemikul Momen Khusus (SRPMK). Sistem Rangka Pemikul Momen Khusus umumnya menggunakan faktor modifikasi respon (R) 8 (SNI 1726;2012), dimana struktur harus berperilaku daktail. Untuk struktur beton bertulang akan mengalami kesulitan dalam pendetailan tulangan. Oleh karenanya dilakukan variasi faktor modifilkasi respon untuk mengetahui pengaruhnya terhadap simpangan struktur, kapasitas momen balok dan daktilitas balok. Struktur gedung 5 lantai dianalisis menggunakan faktor modifikasi respon 4, 5, 6, 7 dan 8. Untuk masing-masing faktor modifikasi respon diperoleh simpangan struktur, kapasitas momen dan daktilitas. Kapasitas momen dan daktilitas elemen balok dihitung berdasarkan tulangan yang diperoleh dari hasil desain. Hasil analisis diperoleh bahwa semakin kecil faktor modifikasi respon (R) akan menghasilkan simpangan struktur makin besar, kapasitas momen makin besar dan daktilitas makin kecil.
\end{abstract}

Kata Kunci: Kelas Situs, Faktor Modifikasi Respon, Simpangan, Kapasitas Momen, Daktilitas.

\begin{abstract}
Based on the wave velocity parameters, Gorontalo City is categorized in the site class SD. This requires the planning of tall buildings to be designed as Special Moment Frame (SMF). Special Moment Frame (SMF) generally uses response modification factor (R) 8 (SNI 1726: 2012), where the structure must be ductile. There will be difficulty for reinforced concrete structures in detailing reinforcement. Therefore, a variety of response modification factors are carried out to determine the effect on structural displacement, beam moment capacity and beam ductility. The 5-story building structure is analyzed using response modification factors 4, 5, 6, 7 and 8. For each response modification factor, it is obtained structural displacement, moment capacity and ductility. The moment capacity and ductility of the beam element is calculated based on the reinforcement obtained from the design results. The analysis result shows that the more the response modification factor $(R)$ decreases, the more the structural diplaeement increases. Meanwhile, the more the capacity moment increases, the more ductility decreases.
\end{abstract}

Keywords: Site Class, Response Modification Factor (R), Displacement, Moment Capacity, Ductility

\section{Pendahuluan}

Pada pembangunan gedung bertingkat sering terjadi permasalahan yaitu apakah bangunan tersebut aman terhadap beban luar seperti akibat angin dan gempa bumi. Semakin tinggi suatu bangunan maka semakin besar efek yang diterima oleh struktur. Oleh karena itu faktor keamanan bangunan harus menjadi pertimbangan para perencana untuk menghindari kerusakan dan kegagalan bangunan. 
Kota Gorontalo termasuk salah satu daerah rawan gempa di Indonesia. Parameter percepatan gempa untuk Kota Gorontalo dilihat dari website Kementrian PU puskim.pu.go.id (Desain Spektra Indonesia) berada pada area parameter Ss $=1,745 \mathrm{~g}$ dan S1 = 0,690 g, dengan letak Kota Gorontalo yang berada pada kondisi Tanah Sedang dapat diklasifikasikan pada Kelas Situs SD. Dari parameter-parameter tersebut dapat dikategorikan bahwa Kota Gorontalo termasuk pada Kategori Desain Seismik (KDS) D.

Untuk bangunan tahan gempa telah dibuat pedoman dalam merencanakan beban gempa. Pedoman yang wajib digunakan di Indonesia saat ini untuk perencanaan beban gempa adalah SNI 1726;2012 dan pedoman untuk perencanaan bangunan gedung beton bertulang mengacu pada SNI 2847;2013. Wilayah yang masuk pada KDS D oleh SNI 2847;2013 pasal 21.1 menetapkan bahwa komponen struktur rangka harus memenuhi persayaratan Sistem Rangka Pemikul Momen Khusus (SRPMK).

Struktur dengan Sistem Rangka Pemikul Momen Khusus (SRPMK) adalah sistem penahan gaya gempa dimana SNI memperbolehkan adanya reduksi beban gempa (Faktor Modifikasi Respon / R) = 8, Reduksi ini dilakukan karena apabila kita melakukan desain dengan mengguna kan $\mathrm{R}=1$ (elastik murni) bisa meng hasilkan kebutuhan struktur yang besar yang pada akhirnya menyebabkan biaya pembangunan yang sangat mahal. Oleh karena itu SNI memperbolehkan adanya reduksi dengan syarat kita melakukan pendetailan yang diperlukan sesuai sistem struktur yang dipilih. Semakin tinggi nilai faktor modifikasi respon $(R)$, pendetailan yang diperlukan pun semakin sulit, karena proses pendetailan yang sulit maka sangat diperlukan tenaga yang profesional. Sehingga perlu untuk diketahui pengaruh Faktor Modifikasi Respon (R) pada balok Sistem Rangka Pemikul Momen Khusus (SRPMK).

\section{METODE}

\section{Pembebanan}

a. Beban mati

Beban yang diperhitungkan disini adalah merupakan berat sendiri strukur dan berat komponen non struktural, yaitu sebagai berikut:

- Berat sendiri komponen

Beban akibat berat sendiri ini dihitung secara otomatis oleh program ETABS.

- Beban Mati Tambahan

Beban mati tambahan yang bukan merupakan elemen struktur seperti finishing lantai, dinding partisi, dan lainlain dihitung berdasarkan berat satuan.

b. Beban Hidup

Beban hidup pada lantai gedung berdasarkan fungsi bangunan perkantoran.

c. Beban Lainnya 


\section{d. Beban Tangga}

Beban tangga dimodelkan dengan memberikan beban terpusat searah gravitasi di balok puncak dan balok landasan.

e. Beban Gempa

Beban gempa yang digunakan didasarkan atas kurva respon spektrum. Dalam menentukan kurva yang disyaratkan memerlukan data-data kondisi geologis lokasi bangunan yang direncanakan. Untuk kebutuhan analisis, data-data kondisi geologis ditentukan sesuai lokasi bangunan yakni terletak di Kota Gorontalo pada kondisi tanah sedang dan sesuai SNI 1726;2012 diklasifikasikan berada pada kelas situs SD. Nilai parameter respons spektral percepatan gempa pada 0,2 detik (S S ) dan parameter respons spektral percepatan gempa pada 1 detik (S 1 ) diperoleh dari peta gerak tanah seismik dan koefisien risiko SNI 1726;2012, dilihat dari website Kementrian $\mathrm{Pu}$ (puskim.pu.go.id), masing-masing adalah : $S s=1,745 S_{1}=0,690$

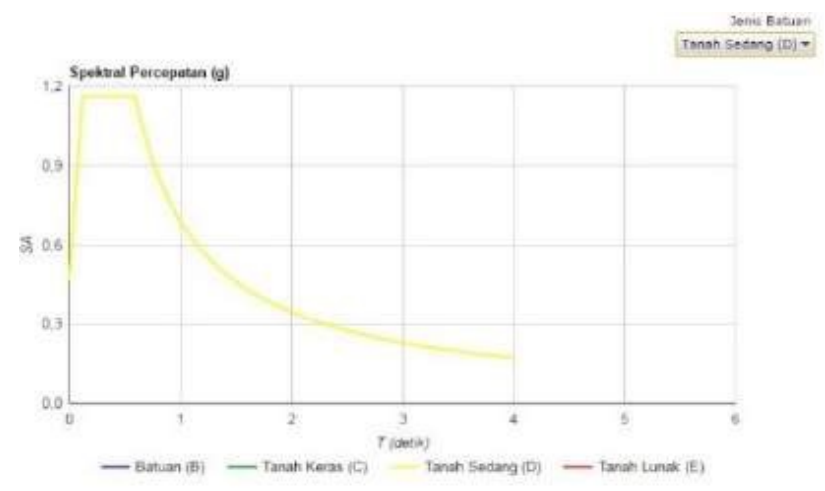

Gambar 5 Grafik Respon Spektrum Kota Gorontalo - Tanah Sedang (Sumber: puskim.pu.go.id)

\section{Pemodelan}

a. Data Material

- Beton

1. Untuk komponen Balok, Kolom dan Pelat digunakan f c ' $30 \mathrm{MPa}$.

2. Untuk kebutuhan analisis linier, digunakan data material default aplikasi.

- Baja

Untuk tulangan menggunakan baja dgn f y $400 \mathrm{Mpa}$. Untuk kebutuhan analisis linier, digunakan data material default aplikasi.

b. Pemodelan Komponen Struktural

Analisis yang dilakukan yakni berdasarkan model Struktur Rangka Pemikul Momen Khusus (SRPMK) dengan variasi nilai $R$ (faktor modifikasi respon) 4, 5, 6,7 , dan 8 dengan nilai parameter lain yang menyesuaikan.

- Dimensi Penampang (Tabel 1) 
Tabel 1 Dimensi Penampang

\begin{tabular}{|c|c|c|}
\hline Penampang & Ukuran & Satuan \\
\hline Kolom & $65 \times 65$ & $\mathrm{~cm}$ \\
\hline Balok Induk & $35 \times 55$ & $\mathrm{~cm}$ \\
\hline Balok Anak & $25 \times 35$ & $\mathrm{~cm}$ \\
\hline Pelat Lantai & 12 & $\mathrm{~cm}$ \\
\hline
\end{tabular}

- Pelat Lantai

Pelat lantai di desain dengan beton ketebalan $120 \mathrm{~mm}$ dengan mutu beton 30 Mpa.

- Massa Efektif Struktur

Massa efektif struktur yang disyaratkan oleh SNI1726;2012 adalah minimal sebesar $25 \%$ dari beban hidupyang digunakan. Dalam pemodelan ini menggunakan massa efektif sebesar $30 \%$ beban hidup dan $100 \%$ beban mati.

- Pengaruh P-Delta

Faktor beban yang diperhitungkan dalam analisis P-Delta adalah sebesar 1,0 untuk beban mati dan untuk beban hidup diijinkan direduksi hingga 0,3 .

- Analisis Mode

Analisis mode menggunakan eigen value, jumlah mode yang diperhitungkan adalah sebanyak 12 mode akan dievaluasi kembali jika rasio partisipasi massa $90 \%$ tidak tercapai.

d. Pemodelan Struktur

- Denah Bangunan

Denah dari struktur bangunan tipikal berlaku untuk semua lantai, yakni terdiri dari 5 bentang untuk arah $x$ dan 5 bentang untuk arah y dengan dimensi yang terlihat pada Gambar 6.

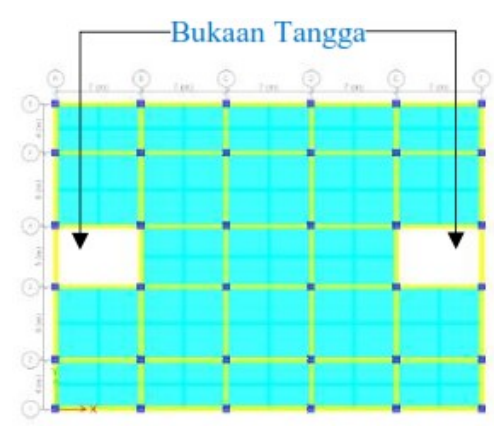

Gambar 6 Denah Bangunan

(Sumber : ETABS 15.0) 


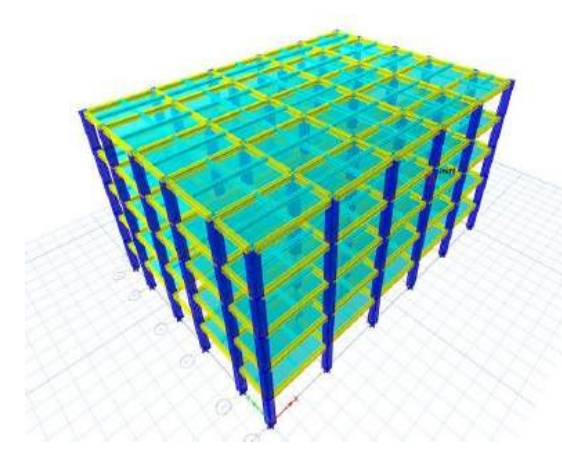

Gambar 7 Tiga Dimensi Bangunan

(Sumber : ETABS 15.0)

\section{Hasil Dan Pembahasan}

\section{Simpangan}

a. Simpangan Antar Lantai

Berdasarkan SNI 1726;2012 simpangan antar lantai tidak boleh lebih dari 0,02 $\times$ $h$ dimana : $h x x x x$ : Tinggi tingkat di bawah lantai $\mathrm{x}$. Drift yang terjadi diperoleh dari tabel ETABS. Hasil Simpangan yang di tampilkan pada Tabel 2.

Tabel 2 Nilai Maksimum Simpangan Antar Lantai

\begin{tabular}{|c|c|c|c|c|c|c|c|}
\hline \multirow{3}{*}{ Story } & \multicolumn{5}{|c|}{ Drift } & \multirow[t]{2}{*}{$\begin{array}{c}\text { D- } \\
\text { ijfin }\end{array}$} & \multirow[t]{2}{*}{ h } \\
\hline & R8 & R7 & R6 & R5 & R4 & & \\
\hline & $\mathrm{mm}$ & $\mathrm{mm}$ & $\mathrm{mm}$ & $\mathrm{mm}$ & $\mathrm{mm}$ & $\mathrm{mm}$ & $\mathrm{m}$ \\
\hline $\begin{array}{c}\text { Story } \\
5\end{array}$ & 6,75 & 7,72 & $\mathbf{9 , 0 0}$ & 10,81 & 13,51 & 80 & 20 \\
\hline $\begin{array}{c}\text { Story } \\
4\end{array}$ & 10,63 & 12,15 & 14,17 & 17,01 & 21,26 & 80 & 16 \\
\hline $\begin{array}{c}\text { Story } \\
3\end{array}$ & 13,82 & 15,79 & 18,42 & 22,10 & 27,63 & 80 & 12 \\
\hline $\begin{array}{c}\text { Story } \\
2\end{array}$ & 14,65 & 16,74 & 19,53 & 23,43 & 29,29 & 80 & 8 \\
\hline $\begin{array}{c}\text { Story } \\
1\end{array}$ & 8,77 & 10,02 & 11,69 & 14,03 & 17,54 & 80 & 4 \\
\hline Base & $\mathbf{0 , 0 0}$ & 0,00 & 0,00 & 0,00 & 0,00 & 0 & 0 \\
\hline
\end{tabular}

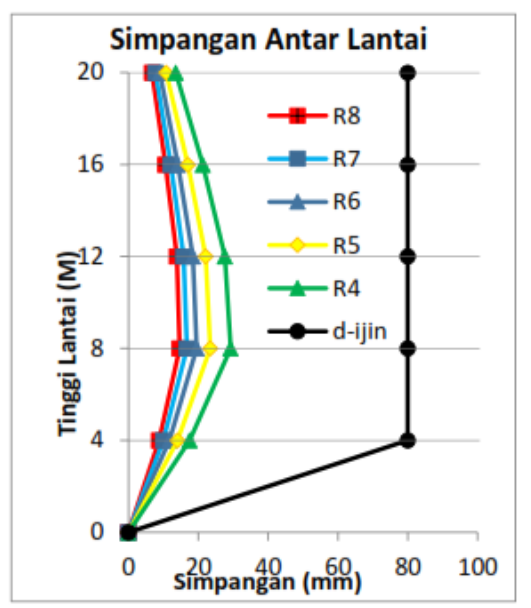

Gambar 8 Grafik Simpangan Antar Lantai untuk semua nilai R

(Sumber : ETABS 15.0) 
Grafik pada Gambar 8 menunjukkan bahwa simpangan antar lantai maksimum dari semua nilai $R$ terjadi pada nilai $R=4$ dengan simpangan antar lantai maksimum berada di lantai 2

b. Simpangan Maksimum (Max Displacement)

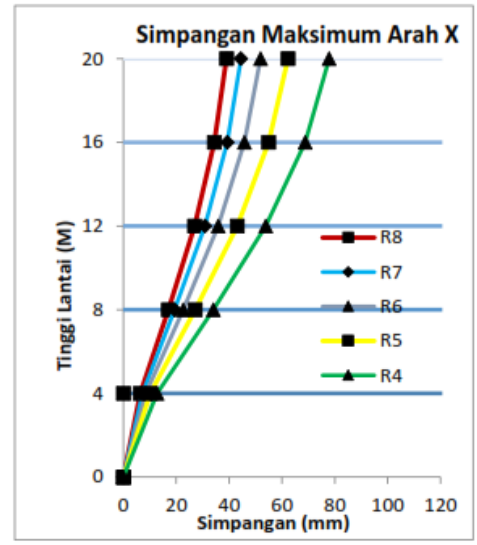

(a)

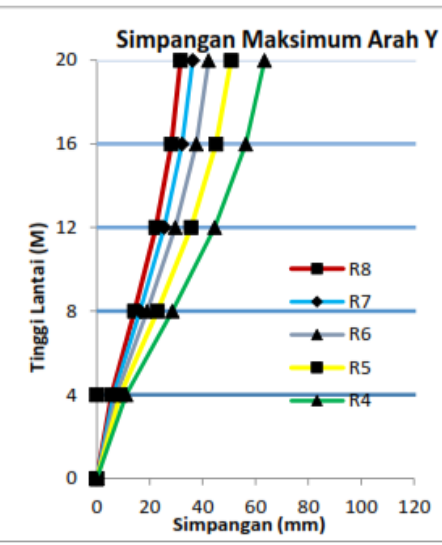

(b)

Gambar 9 Grafik Simpangan Maksimum untuk semua nilai R. (a) Arah X (b) Arah Y (Sumber : ETABS 15.0)

Grafik pada gambar 9 menunjukan simpangan maksimum paling besar adalah pada nilai $R=4$ arah $X$.

\section{Momen Kapasitas dan Daktilitas Balok}

\section{a. Penulangan Balok}

Kapasitas tulangan yang di analisis adalah hasil / output dari ETABS, otomatis telah dihitung oleh ETABS dengan persyaratan Mengacu pada Steel design code AISC 360-05 dan Concrete design code ACl 318-11.

\section{Tabel 3. Tulangan Hasil Etabs}

\begin{tabular}{|c|c|c|c|c|c|}
\hline \multirow{2}{*}{$\begin{array}{c}\text { NILAI } \\
\text { R }\end{array}$} & \multicolumn{2}{|c|}{ Longitudinal } & \multicolumn{3}{|c|}{ Shear } \\
\cline { 2 - 6 } & Top & Bottom & Luas tul. & D.tul & Spasi \\
\hline 8 & 2235 & 1046 & 1170,29 & 10 & 130 \\
\hline 7 & 2405 & 1119 & 1270,72 & 11 & 130 \\
\hline 6 & 2636 & 1219 & 1287,57 & 11 & 130 \\
\hline 5 & 2970 & 1359 & 1380,36 & 11 & 130 \\
\hline 4 & 3499 & 1592 & 2186,34 & 12 & 130 \\
\hline Satuan & $\mathrm{mm} 2$ & $\mathrm{~mm} 2$ & $\mathrm{~mm} 2 / \mathrm{m}$ & $\mathrm{mm}$ & $\mathrm{mm}$ \\
\hline
\end{tabular}

b. Momen Kapasitas

Momen Kapasitas dihitung menggunakan bantuan program Respon 2000, dari data Analisis dan Desain dari program ETABS kemudian diolah dan dianalisis menggunakan RESPONSE 2000. 


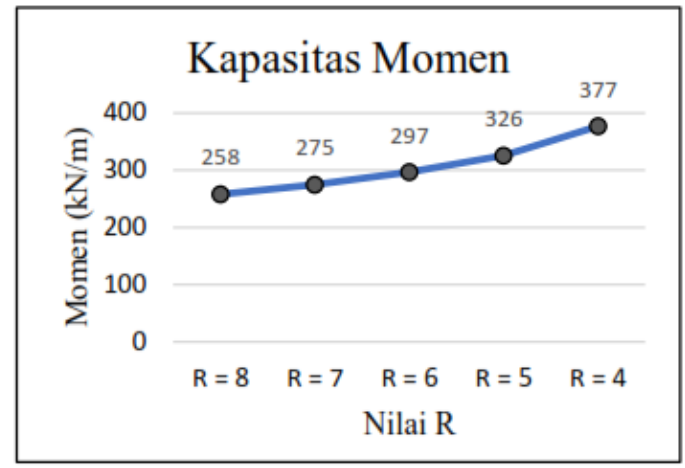

Gambar 10. Kapasitas Momen Balok

(Sumber : Response 2000)

c. Daktilitas Balok

Dari analisis menggunakan bantuan program Respon 2000, didapatkan grafik Load-Max deflection seperti pada gambar 11 Dari grafik tersebut dapat dihitung tingkat daktilitas dari balok yang ditinjau

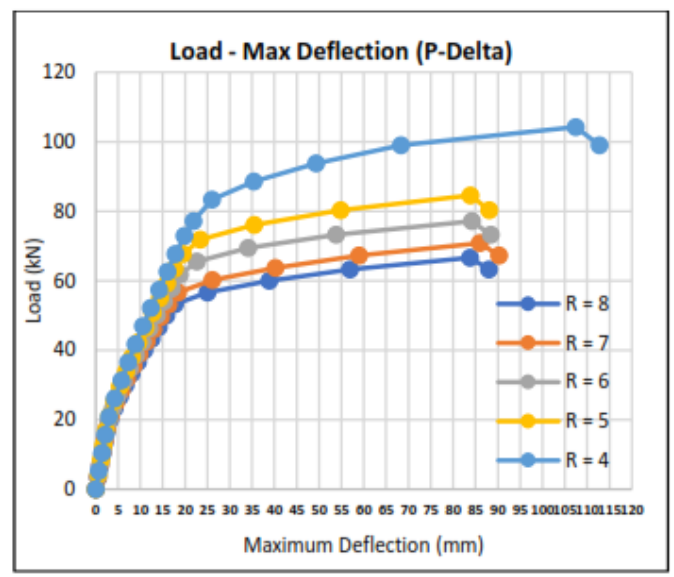

Gambar 11. Grafik Load-Max Displacement

(Sumber : Response 2000)

Diketahui nilai $\square$ Ultimit $=83,818 \mathrm{~mm}$ dan $\square \square$ Leleh $1=17,78 \mathrm{~mm}$ maka :

$$
\text { Daktilitas }=\frac{83,818}{17,78}=4,714
$$

Tabel 4. Daktilitas semua nilai $R$

$$
\begin{array}{|l|l|l|l|l|}
\hline \mathbf{R = 8} & \mathbf{R = 7} & \mathbf{R = 6} & \mathbf{R = 5} & \mathbf{R = 4} \\
\hline 4,714 & 4,673 & 4,461 & 4,303 & 4,124 \\
\hline
\end{array}
$$




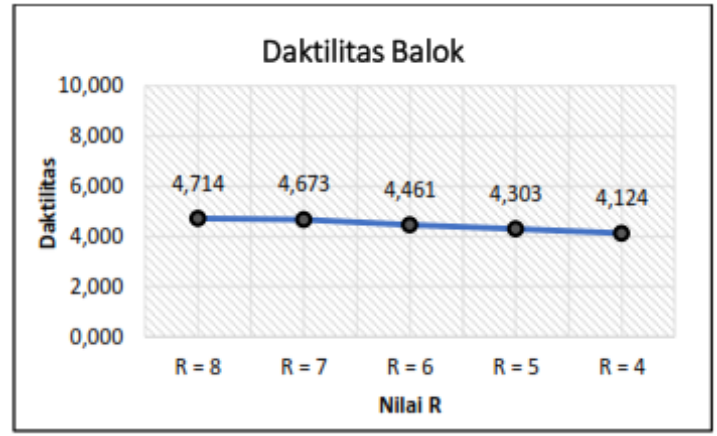

Gambar 12. Daktilitas Balok

(Sumber : Response 2000)

\section{Kesimpulan Dan Saran}

\section{Kesimpulan}

Berdasarkan hasil analisis dan pembahasan yang telah dilakukan dapat diambil beberapa kesimpulan sebagai berikut :

1. Nilai faktor modifikasi respon gempa $(R)$ berpengaruh pada hasil simpangan antar lantai pada struktur SRPMK, dimana untuk nilai $R$ paling kecil $(R=4)$ mengahasilkan simpangan yang paling besar dan untuk nilai $R$ paling besar $(R$ = 8) menghasilkan simpangan paling kecil, namun semua nilai $\mathrm{R}$ masih memenuhi/tidak melewati simpangan ijin. Kebutuhan tulangan balok tinjauan dari hasil Etabs juga menunjukan semakin kecil nilai $\mathrm{R}$ semakin banyak kebutuhan tulangan Longitudinal dan tulangan Geser pada penampang Balok yang ditinjau.

2. Kapasitas Momen balok pada nilai $R=8$ adalah sebesar $258 \mathrm{kN} / \mathrm{m}, \mathrm{R}=7$ sebesar $275 \mathrm{kN} / \mathrm{m}, \mathrm{R}=6$ sebesar $297 \mathrm{kN} / \mathrm{m}, \mathrm{R}=5$ sebesar $326 \mathrm{kN} / \mathrm{m}, \mathrm{R}=4$ sebesar 377 $\mathrm{kN} / \mathrm{m}$. Jadi semakin kecil nilai $\mathrm{R}$ semakin besar Kapasitas Momen yang dihasilkan. Daktilitas balok pada nilai $R=8$ adalah sebesar $4,714, R=7$ sebesar 4,673, $R=6$ sebesar 4,461, $R=5$ sebesar $4,303, R=4$ sebesar 4,124 . Jadi semakin kecil nilai $\mathrm{R}$ semakin kecil pula Daktilitas pada balok tinjauan.

\section{Saran}

1. Penilitian ini belum meninjau kolom, pelat, sambungan, dan elemen struktur secara keseluruhan, sehingga perlu dilakukan penelitian lanjutan untuk mengetahui daktilitas struktur secara global.

2. Melakukan analisis non-linear menggunakan beban dorong (Pushover) sangat disarankan untuk mengetahui tingkat daktilitas struktur secara global.

\section{Daftar Pustaka}

Badan Standar Nasional, (2012). Tata Cara Perencanaan Ketahanan Gempa Untuk Struktur Bangunan Gedung dan Non Gedung.BSN. Jakarta. 
Badan Standar Nasional, (2013). Beban Minimum Untuk Perancangan Bangunan Gedung dan Struktur Lain.BSN. Jakarta.

Badan Standar Nasional, (2013) .Persyaratan Beton Struktural Untuk Bangunan Gedung.BSN. Jakarta.

Departemen Pekerjaan Umum, Desain Spektra Indonesia, http://puskim.pu.go.id/Aplikasi/des ain spektra indonesia 2011/

Hastomi, (2013). Desain Struktur Beton dengan SRPMK, https://hastomiaf.wordpress.com/2013/09/28/desain-strukturbetondengansrpmk-12/.

Nawy, Edward G. (1990). Beton Bertulang: Suatu Pendekatan Dasar. Bandung : Refika Aditama.

Nurlina, S. Suseno, H. Hidayat M. dan Pratama I, (2016). Perbandingan Daktilitas Balok Beton Bertulang dengan Menggunakan Perkuatan CFRP dan GFRP. Skripsi Jurusan Teknik Sipil, Universitas Brawijaya.

Prabowo, A. dan Lase, Y (2016). Tinjauan Nilai Faktor Modifikasi Respon (R) dan Faktor Kuat Lebih ( $\square$ o) pada Struktur Gabungan Rangka Baja dan Rangka Beton Bertulang dengan Analisis Pushover. Skripsi Fakultas Teknik Universitas Tarumanegara dan Universitas Indonesia.

Purwono, R dan Tavio. (2007), Evaluasi Cepat Sistem Rangka Pemikul Momen Tahan Gempa, ITS Press, Surabaya.

Purwono, R. (2005). Perencanaan Struktur beton Bertulang Tahan Gempa, ITS Press, Surabaya.

Setiawan, A. (2016). Perancangan Struktur Beton Bertulang Berdasarkan SNI 2847:2013, Erlangga, Jakarta. 